\title{
Nickel Particle-Based Compact Flexible Antenna for Modern Communication Systems
}

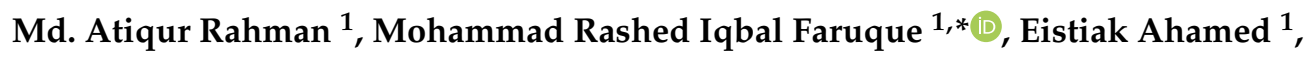 \\ Mohammad Tariqul Islam ${ }^{2}$ aD and Mandeep Singh ${ }^{2}$ \\ 1 Space Science Centre (ANGKASA), Universiti Kebangsaan Malaysia, Bangi 43600, Malaysia \\ 2 Center of Advanced Electronics and Communication Engineering, Universiti Kebangsaan Malaysia, \\ Bangi 43600, Malaysia \\ * Correspondence: rashed@ukm.edu.my; Tel.: +60-389-217-147
}

Received: 3 May 2019; Accepted: 12 June 2019; Published: 15 July 2019

\begin{abstract}
A flexible antenna is a significant part of the new generation of wireless communication systems. Conventional antennas are typically fabricated on available FR-4 and RT/Duroid dielectric materials, where the dielectric constant cannot be selected arbitrarily and the degrees of freedom in designing the antenna are limited, whereas our flexible substrate offers moderate dielectric values by changing the concentration of the raw materials. Synthesised nickel particle-based flexible nickel aluminate $\left(\mathrm{NiAl}_{2} \mathrm{O}_{4}\right)$ is utilized as a substrate material to make an effective antenna for microwave applications. The nickel aluminate substrate was made with $42 \%$ concentration of nickel, and has a dielectric constant of 4.979 and a thickness of $1 \mathrm{~mm}$. The fabricated flexible antenna shows measured bandwidth from 6.50-8.85 GHz. On the other hand, the maximum measured gain and efficiency was $4.75 \mathrm{dBi}$ and $91 \%$, respectively. Finally, that antenna has directional radiation patterns and the presented antenna has a novelty where the nickel aluminate substrate was used for the first time. Thus the compactness of the antenna and its performance with a flexible nature makes it a worthy one to be used in the C-band application.
\end{abstract}

Keywords: compactness; flexible antenna; nickel aluminate $\left(\mathrm{NiAl}_{2} \mathrm{O}_{4}\right)$ material

\section{Introduction}

Over the past few decades, the microstrip patch antenna has been used widely in wireless communication technology because of its optimal size and miniature shape characteristics. At present, flexible antennas are utilized due to their compactness with an advanced flexible substrate that can be easily integrated in electronic devises and cover their functional features. The low-cost flexible antennas are environmentally friendly and easy to manufacture. Various materials like conductive or non-conductive dielectrics are utilized to make this type of flexible antenna. The photolithography or etching processes are used to fabricate the antenna structure and creates large amount of waste due to its subtractive process. As a result, nowadays different types of flexible antennas are manufactured such as paper-based antennas [1], PET(Polyethylene terephthalate) substrates [2], polymer-based antennas [3], wearable antennas [4], fluidic antennas [5], textile antennas [6], carbon nanotube (CNT) antennas [7] and nickel-based metamaterial [8] for increasing the flexibility [9], reducing the waste, manufacturing cost and using low-cost materials.

In the developing field of wireless technology, a goal is to make flexible antennas having special properties with respect to those of bulk or single particle species. A low-cost paper-based flexible antenna for $2.45 \mathrm{GHz}$ frequency band WLAN (wireless local area network) applications was presented by Anagnostou et al. The projected antenna was an IFA(Inverted-F antenna) with a backside ground plane and a topside metallic layer. The simulated and measured return loss have been in good 
agreement, with a $-10 \mathrm{~dB}$ bandwidth that covers the entire WLAN frequency range. It detected only a $2 \%$ shift from what was expected [10]. Again, a flexible antenna based on a zero-order resonator was manufactured on liquid crystal polymer substrate (thickness of $100 \mu \mathrm{m}$ ) and the total dimension of the antenna was $30 \times 30 \mathrm{~mm}^{2}$ presented by Choi et al. Once the proposed antenna is flat, it has the average and peak gain of $-1.84 \mathrm{dBi}$ and $4.98 \mathrm{dBi}$, respectively, at the resonance point $3.18 \mathrm{GHz}$. While the antenna is bent with +900 , then the average and peak gains are sequentially $-2.46 \mathrm{dBi}$ and $2.99 \mathrm{dBi}$ [11]. In 2012, the presented antenna was a compact and flexible CPW (coplanar waveguide)-fed, UWB (Ultra-wideband) antenna, which consists of an elliptical patch and a modified ground plane to achieve impedance bandwidth between $2.52 \mathrm{GHz}$ to $13.35 \mathrm{GHz}$. The substrate was composed of $0.78 \mathrm{~mm}$ thickness denim textile which has a permittivity of 1.8 and tangent loss of 0.07 at $2.4 \mathrm{GHz}$ [12]. A flexible coplanar-fed dual band antenna was built on Kaptonr polyimide substrate for $2.45 \mathrm{GHz}$ and $5.80 \mathrm{GHz}$ ISM bands by Mesquita et al. in 2013 [13]. A flexible antenna proposed on $101 \mu \mathrm{m}$ Ultralam 3850 for microwave imaging was reported by Porter et al. in 2014 . The total antenna size was $24 \times 32 \mathrm{~mm}^{2}$. The simulated and measured $\mathrm{S}_{11}$ for the flexible antenna was over the $1.5 \mathrm{GHz}$ to $4.5 \mathrm{GHz}$ frequency band. The author reported a near omnidirectional and broadside near-field radiation pattern with an efficiency of $47 \%$ from simulations, when in interaction with skin [14]. In 2015, Jung et al. offered a simple approach to make an implantable, yet compact and flexible, monopole antenna consisting of meandered strips and a coupling patch, fabricated on a thin coating of ultrathin Parylene C film substrate. Moreover, the antenna was first designed to operate in air and tuned at later stage after studying the effects when implanted under porcine skin. The results of the S11 of the flexible dual band (2.4 GHz and $5.8 \mathrm{GHz}$ ). In addition, the $2.4 \mathrm{GHz}$ and $5.8 \mathrm{GHz}$ associated measured maximum radiation gains were $-5.4 \mathrm{dBi}$ and $3.8 \mathrm{dBi}$, respectively. The characteristics of the proposed antenna have also shown negligible change under different bending conditions [15]. A modified microstrip patch antenna was designed on Polyethylene terephthalate substrate for 5G applications in 2017 . The $60 \times 75 \mathrm{~mm}^{2}$ antenna was operated within 7.0 to $13 \mathrm{GHz}$ and exhibits an almost omnidirectional radiation pattern with an average gain of $5 \mathrm{dBi}$ [16]. Metallized form helps to design pico-cell based antenna operates at GSM850, GSM900, GSM1800, GSM1900, UMTS (Universal Mobile Telecommunications System), Bluetooth/WLAN, WiMAX (Worldwide Interoperability for Microwave Access), and Wi-Fi (wireless fidelity) which was shown total efficiency $75 \%$ [17].

In this paper, a new flexible antenna is introduced based on nickel aluminate $\left(\mathrm{NiAl}_{2} \mathrm{O}_{4}\right)$ substrate with $42 \%$ nickel concentration which has been synthesized by the sol-gel method. The prepared flexible antenna shows the simulated bandwidth of $1.67 \mathrm{GHz}$ from 7.05 to $8.72 \mathrm{GHz}$, whereas the resonance point is at $8.15 \mathrm{GHz}$. The measured results show the bandwidth of $2.35 \mathrm{GHz}$ from 6.50 to $8.85 \mathrm{GHz}$, whereas the resonance is sequentially at $7.75 \mathrm{GHz}$. As a result, the fabricated flexible antenna is applicable for $\mathrm{C}$-band application. The measured maximum and average antenna gain are $4.75 \mathrm{dBi}$ and $3.75 \mathrm{dBi}$ and the radiation characteristics have a directional pattern.

\section{Design of Flexible Antenna}

\section{Flexible Antenna at $42 \%$ Concentration of Nickel}

The schematic structure of the microstrip-fed patch antenna is shown in Figure 1a-b. This antenna is designed on a flexible nickel aluminate $\left(\mathrm{NiAl}_{2} \mathrm{O}_{4}\right)$ material as a substrate material, where the molar ratio of [0.42(nickel):0.58(aluminium nitrate)]. Nickel aluminate $\left(\mathrm{NiAl}_{2} \mathrm{O}_{4}\right)$ material is chosen as substrate material with permittivity of 4.97 , loss tangent of 0.007 and thickness of $0.5 \mathrm{~mm}$.

The antenna is excited with a microstrip feed line printed on the bottom layer of substrate and a $50 \Omega$ SMA (SubMiniature version A) connector connected with the feed line and ground plane each other. In the figure, the antenna structure consists of a $19 \times 13 \mathrm{~mm}^{2}$ rectangular patch and a $25 \times 8.5 \mathrm{~mm}^{2}$ rectangular ground plane as well, the total length of the feed line is $6.5 \mathrm{~mm}$, whereas the width is $4 \mathrm{~mm}$. Moreover, the gaps between the patch and nickel aluminate substrate edge are $3 \mathrm{~mm}$. Figure $1 \mathrm{c}-\mathrm{d}$ shows the fabricated antenna prototype and Table 1 demonstrates the detail design specification of the antenna. 


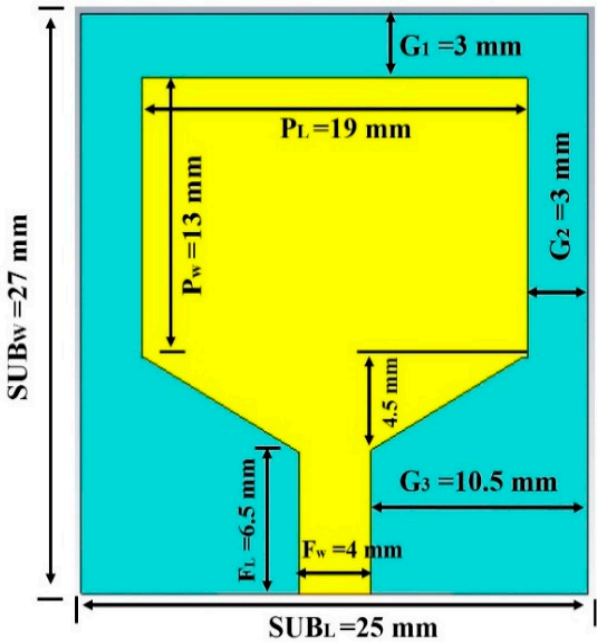

(a)

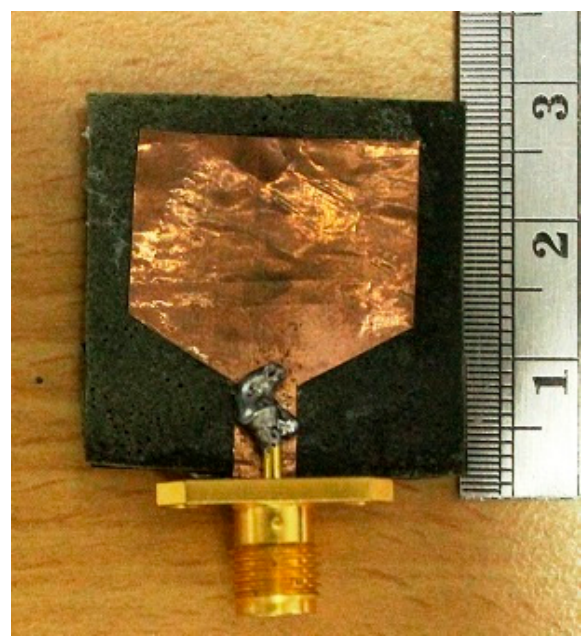

(c)

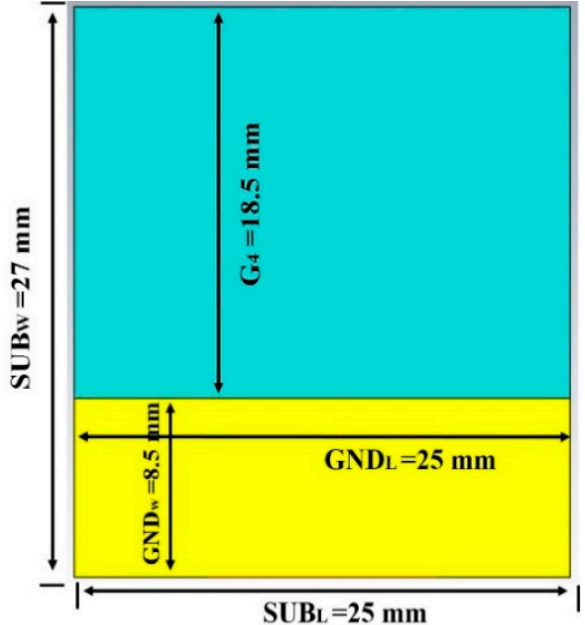

(b)

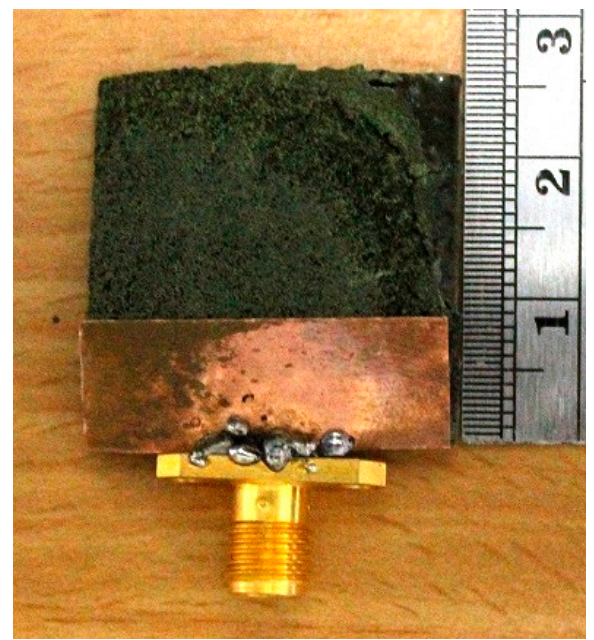

(d)

Figure 1. Proposed antenna schematic (a) front view (b) back view of graphic structure and fabricated prototype (c) front view (d) back view on flexible nickel aluminate material at $42 \%$ concentration of nickel.

Table 1. Design specification of the proposed flexible antenna at $42 \%$ concentration of nickel.

\begin{tabular}{cccc}
\hline Parameters & Size $(\mathbf{m m})$ & Parameters & Size $(\mathbf{m m})$ \\
\hline Substrate Length $\left(\mathrm{SUB}_{\mathrm{L}}\right)$ & 25 & Ground Length $\left(\mathrm{GND}_{\mathrm{L}}\right)$ & 25 \\
Substrate Width $\left(\mathrm{SUB}_{\mathrm{W}}\right)$ & 27 & Ground Width $\left(\mathrm{GND}_{\mathrm{W}}\right)$ & 8.5 \\
Patch Length $\left(\mathrm{P}_{\mathrm{L}}\right)$ & 19 & Gap $\left(\mathrm{G}_{1}\right)$ & 3.0 \\
Patch Width $\left(\mathrm{P}_{\mathrm{W}}\right)$ & 13 & Gap $\left(\mathrm{G}_{2}\right)$ & 2.0 \\
Feed Line Length $\left(\mathrm{F}_{\mathrm{L}}\right)$ & 6.5 & Gap $\left(\mathrm{G}_{3}\right)$ & 10.5 \\
Feed Line Width $\left(\mathrm{F}_{\mathrm{W}}\right)$ & 4.0 & Substrate Thickness $(\mathrm{T})$ & 1.0 \\
\hline
\end{tabular}

\section{Methodology and Measurement}

Electromagnetic simulation helps estimating the fundamental field quantities from Maxwell's equation adopting some numerical methods. It is important to undertake a highly exact design and investigation of confounded microwave and RF (radio frequency) printed circuit, antenna and other electronic segments. This also clarifies the electromagnetic wave propagation and interactions with metamaterials. Finite-difference time-domain method-based CST (computer simulation technology) 
Microwave Studio is used for obtaining the reflection coefficient, VSWR (voltage standing wave ratio), gain, efficiency and radiation patters for the designed antennas. A vector network analyzer Agilent P-series VNA (Vector network analyzer) (Agilent N5227A) equipped with two ports is used for the measurement. The calibration prior is required for error-free measurement. Scattering parameters return loss, VSWR and the phase of input impedance measurements are achieved by linking the fabricated antenna to port- 1 of the network analyzer via a semi-rigid cable.

The radiation behaviors of the designed flexible antennas at $42 \%$ concentration of nickel have been measured in an anechoic chamber bounded near field measurement lab (UKM Satimo Star Lab) shown in Figure 2. The fabricated antenna is placed on the test board which is located at the center of a circular "arch" that covers 16 probes and the spacing between two probes is $22.5^{\circ}$. This spacing is appropriate for small antenna testing. For larger antennas, the position of the probe array can be mechanically offset. The antenna is rotated horizontally through $360^{\circ}$ and summary of $360^{\circ}$ rotation and array of 16 probes give a full wave 3D-scan of the under-tested antenna. To realize unlimited near-field sampling, the consuming standard spherical ray propagation technique and software are utilized to feed the radiation pattern that are entirely defined by a set of modal coefficients. To increase the efficiency and reduce the reflected signal of the designed antenna the absorbers are used to absorb the unwanted signal inside the anechoic chamber.

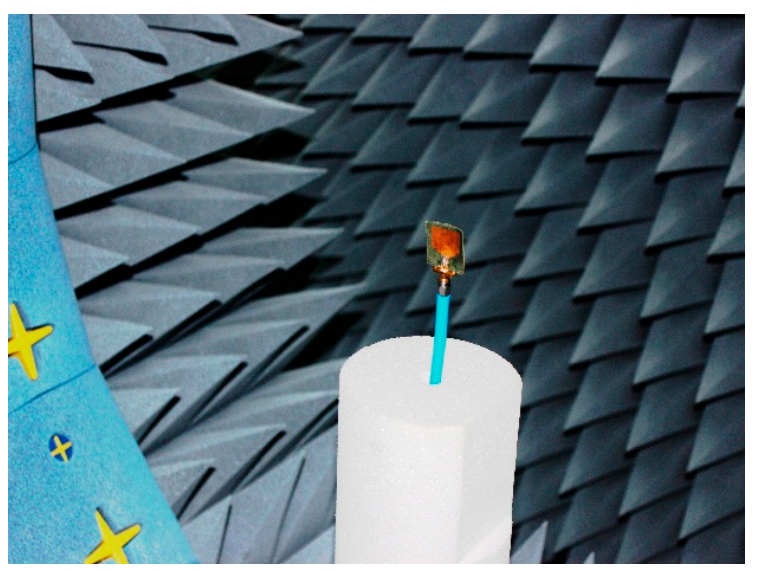

Figure 2. Measurement setup of designed flexible antennas at $42 \%$ concentration of nickel in Satimo Star Lab.

\section{Results and Discussion}

\subsection{Preparation of Flexible Nickel Aluminate $\left(\mathrm{NiAl}_{2} \mathrm{O}_{4}\right)$}

The sol-gel method is used to manufacture the final substrate [18]. Figure 3 presents a flow chart of the synthesis steps of nickel aluminate powder by the sol-gel method. For the preparation of nickel aluminate composite, initially two raw materials aluminium nitrate nonahydrate $\mathrm{Al}\left(\mathrm{NO}_{3}\right)_{3} \cdot 9 \mathrm{H}_{2} \mathrm{O}$ and nickel nitrate hexahydrate $\mathrm{Ni}\left(\mathrm{NO}_{3}\right)_{2} \cdot 6 \mathrm{H}_{2} \mathrm{O}$ were used in a molar ratio of [0.42(nickel):0.58 (aluminium nitrate)] for $42 \%$ concentration of nickel to make the solution. The subsequent complex solution became viscous, has transparent characteristics, and exhibits a light green colour. The water evaporates from the ready solution, and it is heated up to $90{ }^{\circ} \mathrm{C}$ and stirred endlessly for about 4 hours. The water completely evaporated and gave the impression of a greenish gel. The gel is placed into an alumina crucible furnace at $150{ }^{\circ} \mathrm{C}$ for the rest of the chemical reaction and for obtaining fine powder. At that time, the precursor was ground appropriately and for 1 hour calcined at $450{ }^{\circ} \mathrm{C}$, and then we waited until the chemical reaction finished. Then dissolved polyvinyl acetate (PVA) adding to the synthesized $\mathrm{NiAl}_{2} \mathrm{O}_{4}$ powder and made the fabricated substrate followed by stirring. Figure 3 shows the total preparation process of nickel aluminate $\left(\mathrm{NiAl}_{2} \mathrm{O}_{4}\right)$ powder and fabricated nickel aluminate $\left(\mathrm{NiAl}_{2} \mathrm{O}_{4}\right)$ material at a concentration of $42 \%$ nickel, termed $\mathrm{Ni}_{42}$. 


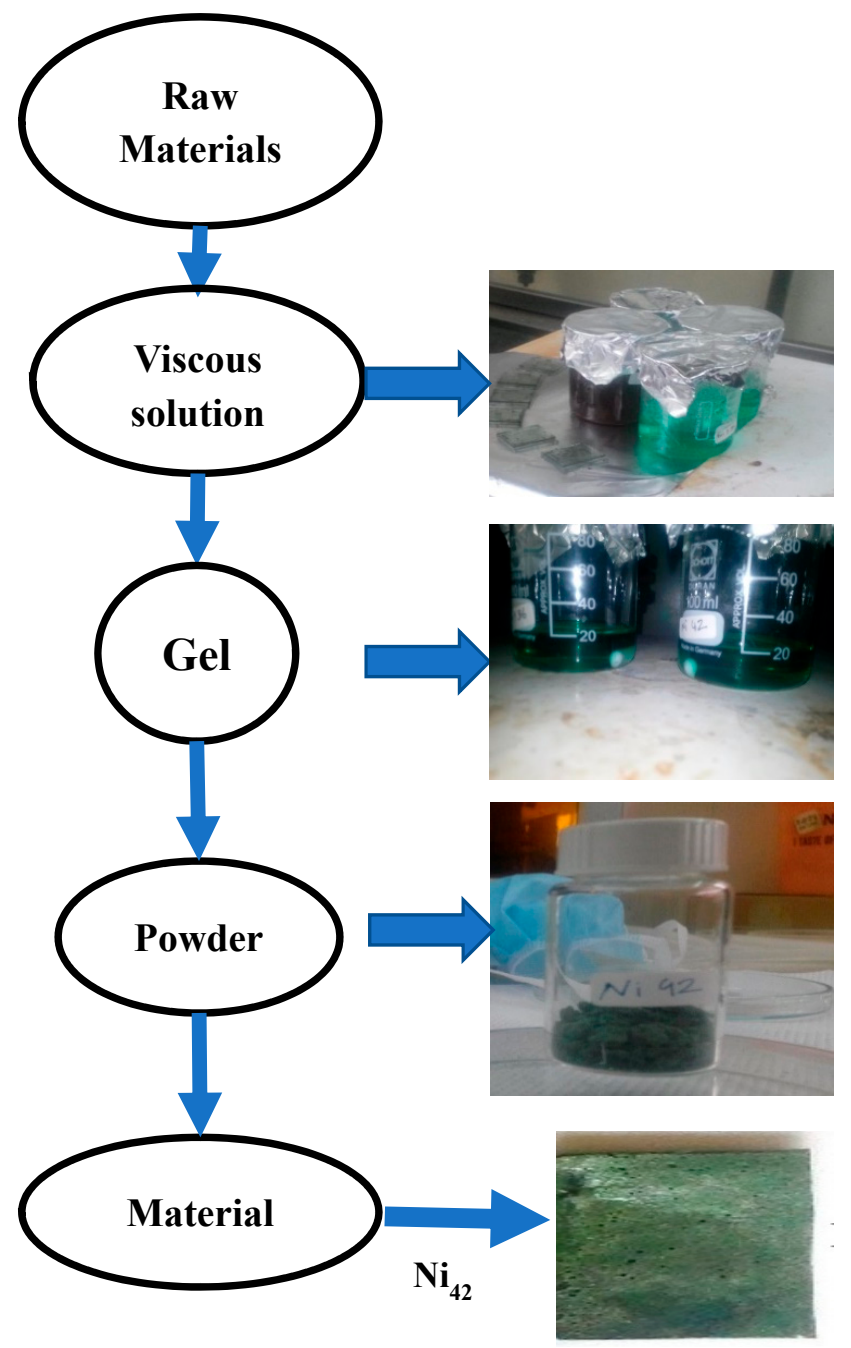

Figure 3. Preparation flowchart and process of fabrication of nickel aluminate $\left(\mathrm{NiAl}_{2} \mathrm{O}_{4}\right)$ material.

Table 2 shows the relative molecular mass (JMR) and the volume of solvent and other materials used to produce solutions for calculation purposes. In this research, aluminium nitrate nonahydrate $\mathrm{Al}\left(\mathrm{NO}_{3}\right)_{3} \cdot 9 \mathrm{H}_{2} \mathrm{O}$ and nickel nitrate hexahydrate $\mathrm{Ni}\left(\mathrm{NO}_{3}\right)_{2} \cdot 6 \mathrm{H}_{2} \mathrm{O}$ were taken as raw materials to make the $\mathrm{NiAl}_{2} \mathrm{O}_{4}$ composite specimens using the well-known sol-gel method.

Table 2. JMR information of the raw material.

\begin{tabular}{cccc}
\hline Materials & JMR & moles & Ni \\
\hline Nickel (0.42) \\
\hline Aluminitrate hexahydrate $\left(\mathrm{Ni}\left(\mathrm{NO}_{3}\right)_{2} \cdot 6 \mathrm{H}_{2} \mathrm{O}\right)$ & 290.81 & 0.0375 & $4.580 \mathrm{gm}$ \\
Citric acid $\left(\mathrm{C}_{6} \mathrm{H}_{8} \mathrm{O}_{7}\right) \cdot \mathrm{H}_{2} \mathrm{O}$ & 375.13 & 0.0375 & $8.159 \mathrm{gm}$ \\
Polyvinyl alcohol $\left(\mathrm{C}_{4} \mathrm{H}_{6} \mathrm{O}_{2}\right)_{n}$ & 210.14 & 0.0375 & $7.88025 \mathrm{gm}$ \\
Distil water & 86.09 & - & - \\
\hline
\end{tabular}

\subsection{Flexible Antenna at $42 \%$ Concentration of Nickel}

Numerical and measured results of the fabricated flexible antenna, where the concentration of nickel is $42 \%$, are shown in Figure 4. The simulated resonance bandwidth is from 7.05 to $8.72 \mathrm{GHz}$ (bandwidth of $1.67 \mathrm{GHz}$ ), whereas the measured resonance bandwidth is from 6.50 to $8.85 \mathrm{GHz}$ (bandwidth of $2.35 \mathrm{GHz}$ ). As a result, from the resonance bandwidth it can be said that the fabricated antenna is applicable for C-band $(6.50 \mathrm{GHz}$ to $8.85 \mathrm{GHz})$ applications. In addition, the simulated 
resonance point is at $8.15 \mathrm{GHz}$, but the measured resonance point is at $7.75 \mathrm{GHz}$. Besides, from the results it is seen that there is a variation between the simulated and measured results. There are some pores in the substrate, which is why the effective area of the fabricated antenna is reduced than the simulated one. The impedance mismatch between the SMA connectors, the feedline fabrication and soldering tolerance of the antenna along with improper calibration of the VNA and Satimo chamber were possible reasons for the discrepancy of the simulated and measured results.

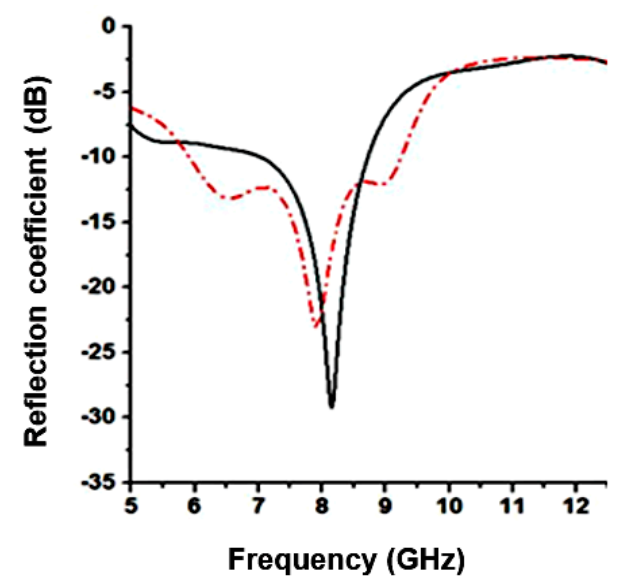

Figure 4. Simulated and measured return loss of the designed flexible antenna at $42 \%$ concentration of nickel.

The measured and simulated gain of the antenna are shown in Figure 5a. Antenna gain is related to size of the antenna, substrate material properties and multiple layer of the substrate. The proposed compact antenna is designed on flexible nickel aluminate $\left(\mathrm{NiAl}_{2} \mathrm{O}_{4}\right)$ material where the ratio of nickel is $42 \%$. The antenna has simulated maximum and average gain and are sequentially, $5.25 \mathrm{dBi}$ and $4.25 \mathrm{dBi}$. In addition, the measured maximum and the average gain are $4.75 \mathrm{dBi}$ and $3.75 \mathrm{dBi}$, respectively. Antenna efficiency is central importance in predicting radio communications reliability. It is the measurement of conversion of electrical current to radiated electromagnetic wave. New materials and smaller antennas are of significant interest to reduce e-waste and to make fabrication easier. A low-efficiency antenna has reduced gain and so the communications range is reduced. The fundamental limits on the maximum radiation efficiency are the various antenna parameters such as bandwidth, gain, $Q$ factor and so on. Figure $5 \mathrm{~b}$ shows the total efficiency of the proposed flexible antenna where the measured average efficiency is $85 \%$ and the maximum efficiency is $91 \%$, whereas the simulated average efficiency is $85 \%$ and the maximum efficiency is $96 \%$.

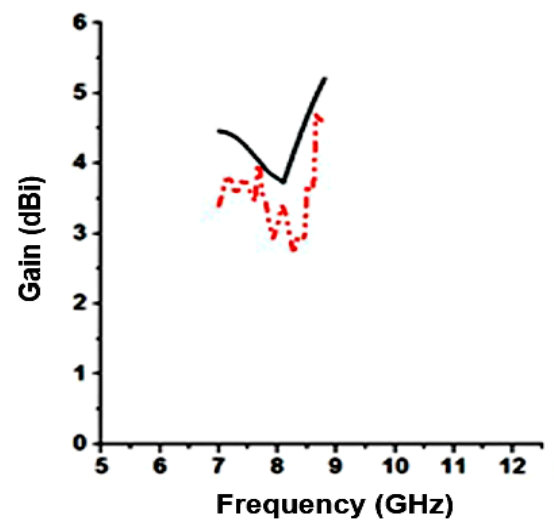

(a)

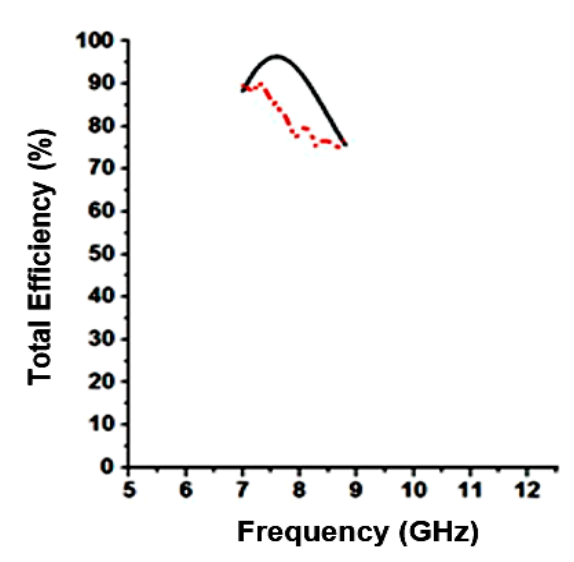

(b)

Figure 5. Measured and simulated, (a) gain and (b) total efficiency of the designed flexible antenna; at $42 \%$ concentration of nickel. 
The current distribution of the designed antenna at the resonant frequencies $8.15 \mathrm{GHz}$ is shown in Figure 6. The patch is a short resonant length of low-impedance and have high magnitude in the edges and maximum current distribution at the center of the patch at the resonant frequency. The distribution strongly depends on the height of substrate which is obtainable for the antenna size. The electric surface current density at each position on the lower surface is equal to the magnetic field under the patch.

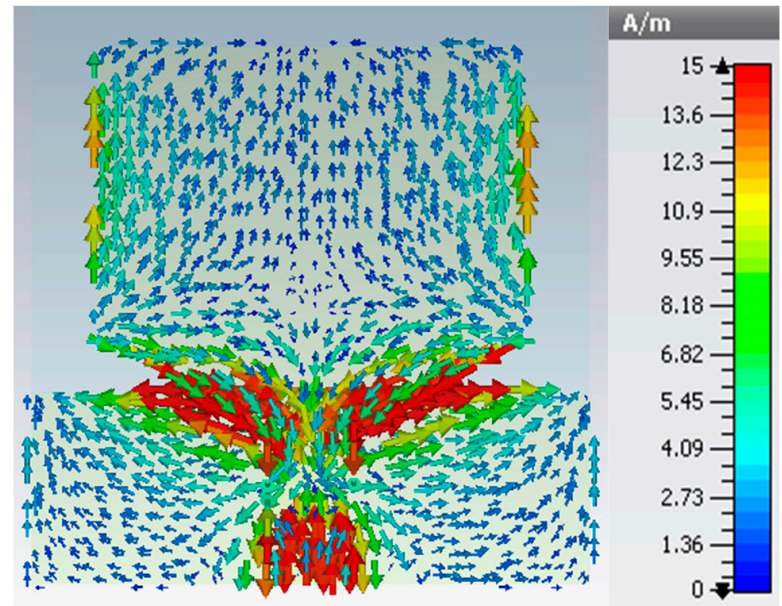

Figure 6. Surface current distribution in $8.15 \mathrm{GHz}$ at $42 \%$ concentration of nickel.

Both simulated and measured radiation patterns in the case of co-polarization and cross-polarization in the E-plane and H-plane are compared in Figure 7a,b respectively, whereas $\mathrm{E} \theta$ represents the co-polarization and $\mathrm{E} \varphi$ represents the cross-polarization. The co-polarization is more noteworthy than the cross-polarization in both E-plane and H-plane. The radiation pattern exhibited that at $7.75 \mathrm{GHz}$, the current is well distributed over the patch, and the patterns are almost directional. Moreover, a better radiation pattern depends basically on precisely situating the probe, and reducing distortions in the field presented by the room or track.

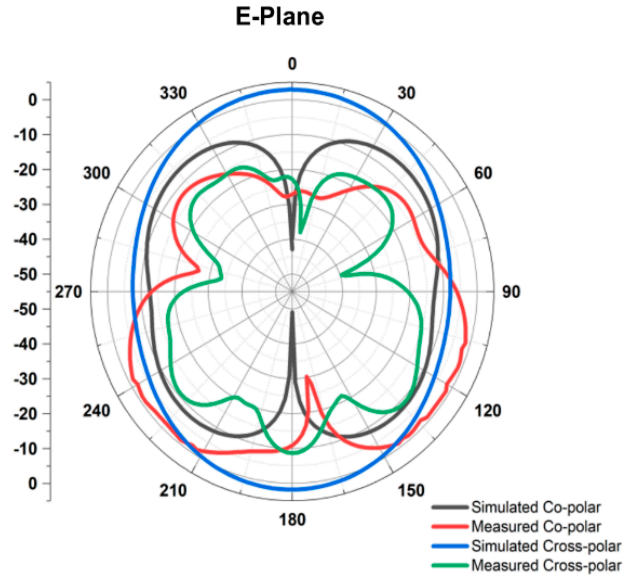

(a)

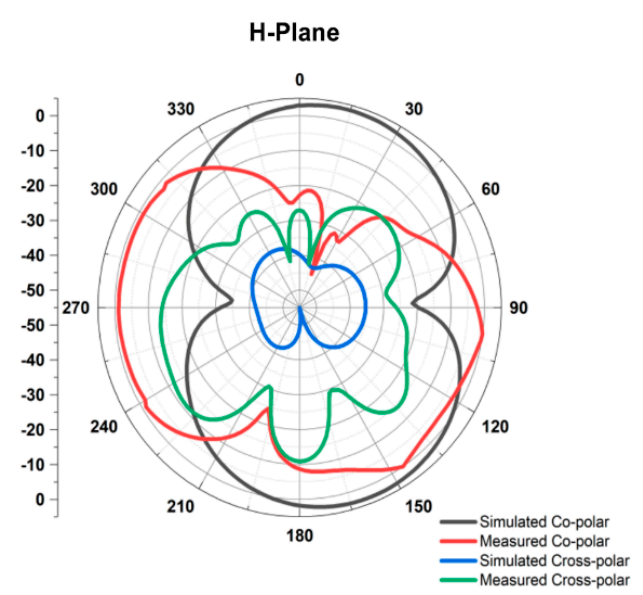

(b)

Figure 7. Simulated and measured radiation pattern of the proposed flexible antenna in $7.75 \mathrm{GHz}$ in (a) E-Plane and (b) H-plane.

\subsection{Parametric Analysis of the Proposed Flexible Patch Antenna}

Figure $8 \mathrm{a}-\mathrm{d}$ present the parametric analysis of the designed antenna, which is necessary to understand the effects of different elements in antenna geometry and how the elements affect the antenna performances. In Figure $8 \mathrm{a}-\mathrm{b}$ a rectangular radiating patch is attached where the current is 
distributed well around the patch and expands the bandwidth and gain. The dimension of the ground plane is not so high, so less current is distributed on the ground plane and has less effect on the antenna performance. At the time of operation, the antenna acts like a capacitor or inductor, when the signals with phases are passes through the antenna. At low frequency operation the antenna radiating patch is not a good conductor, so conductivity is improved by the ground or additional metal strips. In Figure $8 \mathrm{c}$ the radiating patch structure is cut like triangle and finally a metallic strip relates to the upper edge of the triangular patch and generates a slot as shown in Figure 8d. The performance of all antenna structures is displayed in Figure 9. From Figure 9, the proposed antennas have optimal compute results in respect of VSWR. If the VSWR is lower than 2.0, the antenna impedance match is considered perfect and antenna performed well but when VSWR are increased more than 2.0 then the antenna starts to reflect more power and therefore does not transmit. Table 3 represents the band of frequencies; where VSWR are lower than 2.0 at different structural arrangement of the proposed antenna configuration.

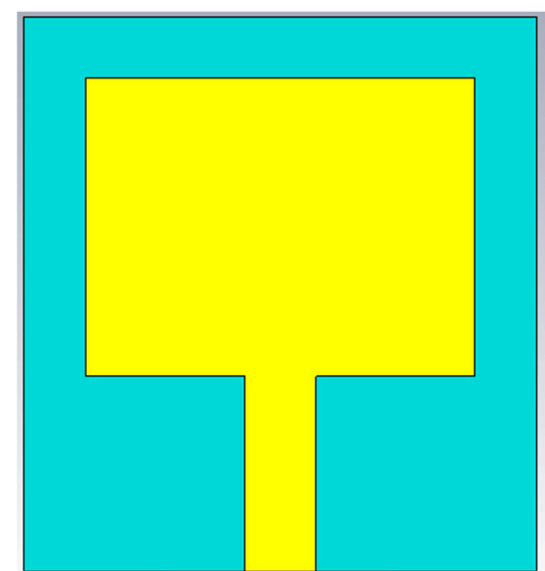

(a)

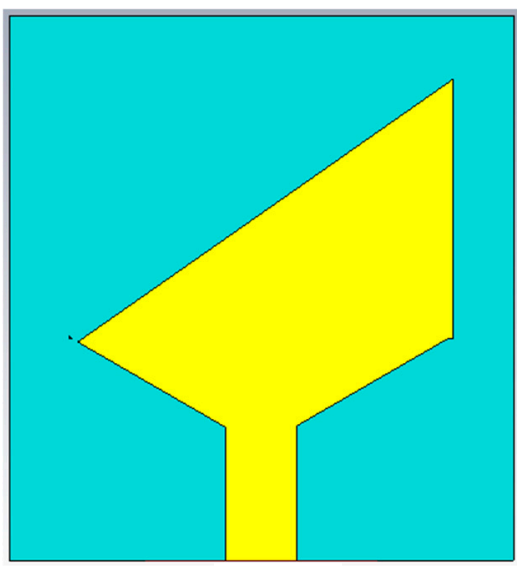

(c)

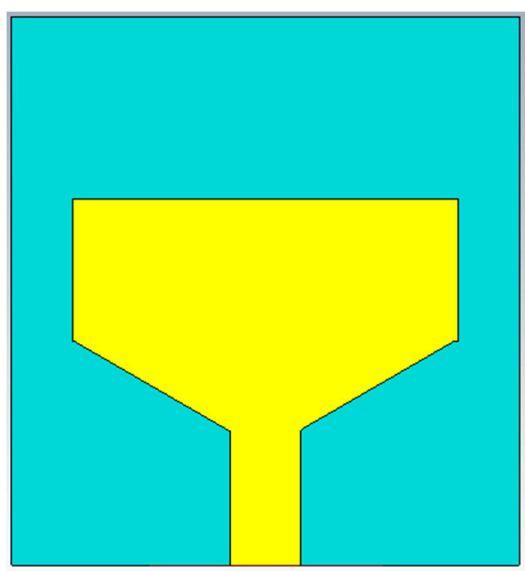

(b)

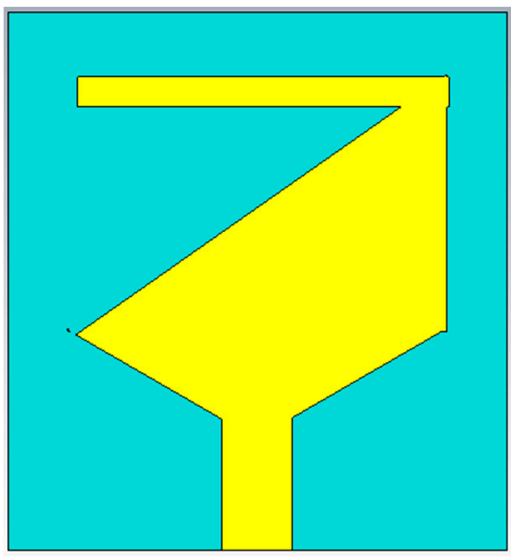

(d)

Figure 8. Structural parametric analysis of antenna (a) patch structure-1 (b) patch structure-2 (c) patch structure-3 and (d) patch structure-4.

Table 3. Comparison of the radiating patch effects on voltage standing wave ratio.

\begin{tabular}{cc}
\hline Structural Parametric Analysis & Frequency Regimes (VSWR < 2) \\
\hline Patch Strucutre-1 & $5 \sim 5.64 \mathrm{GHz}$ \\
Patch Strucutre-2 & $5 \sim 8.51 \mathrm{GHz}$ \\
Patch Strucutre-3 & $7.52 \sim 8.91 \mathrm{GHz}$ \\
Patch Strucutre-4 & $5.80 \sim 9.30 \mathrm{GHz}$ \\
\hline
\end{tabular}




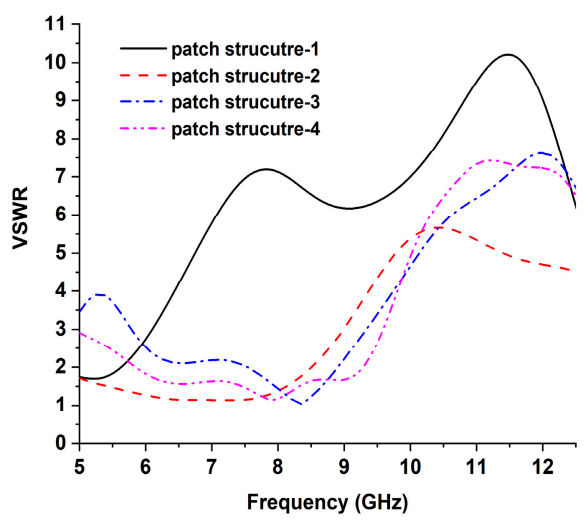

Figure 9. The effects of different radiating patch structures of antenna voltage standing wave ratio (VSWR).

To confirm the novelty of the proposed flexible antennas, Table 4 summarizes the performances of the proposed antennas in terms of size in the antenna, impedance bandwidth, gain, efficiency, radiation patter and application. From Table 4, it can be seen that the proposed antennas are compact in size, have larger bandwidth, acceptable gain, efficiency and directional radiation patterns. The antennas are fabricated on the flexible nickel aluminate $\left(\mathrm{NiAl}_{2} \mathrm{O}_{4}\right)$ material at $42 \%$ concentration, whereas the operating frequency from $5 \mathrm{GHz}$ to $12 \mathrm{GHz}$. In addition, the flexible antenna has efficiency of $91 \%$ as well as gain of $4.75 \mathrm{dBi}$, respectively. Besides, the antenna has a directional radiation pattern and is applicable for C-band (at $42 \%$ concentration) application.

Table 4. Performance summary of the proposed flexible material-based patch antennas.

\begin{tabular}{cc}
\hline Properties & Flexible Antenna at $\mathbf{4 2} \%$ Concentration of Nickel \\
\hline Total Dimension & $25 \times 27 \mathrm{~mm}^{2}$ \\
Substrate Material & Nickel aluminate $\left(\mathrm{NiAl}_{2} \mathrm{O}_{4}\right)$ \\
Return loss & Less than $-10 \mathrm{~dB}$ \\
VSWR & Less than 2.0 \\
Input Impedance & $50 \Omega$ \\
Operating Frequency & $512.5 \mathrm{GHz}$ \\
Resonance Frequencies & $7.75 \mathrm{GHz}$ \\
Measured Bandwidth & $2.35 \mathrm{GHz}$ \\
Maximum Gain (dBi) & $4.75 \mathrm{dBi}$ \\
Total Efficiency & $91 \%$ \\
Radiation Pattern & Directional \\
Applications & C-Band \\
\hline
\end{tabular}

Table 5 demonstrates the comparison between the developed flexible material antenna with the existing various flexible material antennas. From the table, the largest antenna was presented by Kaur et al. But the antenna gain was high, and bandwidth was narrow. Porter et al. developed an antenna on flexible Rogers Ultralam 3850 material whose dimension was $24 \times 32 \mathrm{~mm}^{2}$, bandwidth of $3.0 \mathrm{GHz}$, and gain of $2.7 \mathrm{dBi}$, for microwave imaging applications. Furthermore, Simorangkir et al. also established an $80 \times 67 \mathrm{~mm}^{2}$ antenna on flexible polydi methylsiloxane material, which had 6.0 GHz wide bandwidth and $4.53 \mathrm{dBi}$ gain for UWB applications. In this research, the antenna is developed using flexible nickel aluminate as a substrate material. The reported antennas are compact in size $\left(25 \times 27 \mathrm{~mm}^{2}\right)$, large bandwidth, high gain and applicable for C-band application. 
Table 5. Comparison between the proposed and existing material antennas.

\begin{tabular}{|c|c|c|c|c|c|}
\hline References & Substrate Material & $\begin{array}{l}\text { Dimensions } \\
\left(\mathrm{mm}^{2}\right)\end{array}$ & $\begin{array}{l}\text { Bandwidth } \\
\text { (GHz) }\end{array}$ & $\begin{array}{l}\text { Gain } \\
\text { (dBi) }\end{array}$ & Applications \\
\hline Anagnostou et al. [10] & Organic paper & $46 \times 30$ & 0.42 & 1.2 & WLAN \\
\hline Choi et al. [11] & Liquid crystal polymer & $30 \times 30$ & 0.07 & 4.98 & Wi-Fi \\
\hline Porter et al. [14] & Rogers Ultralam 3850 & $24 \times 32$ & 3.0 & 2.7 & Microwave Imaging \\
\hline Jung et al. [15] & Ultrathin Parylene $C$ film & $26.48 \times 18.20$ & 3.4 & 3.8 & WLAN \\
\hline Kaur et al. [19] & Teflon & $85 \times 90$ & 0.53 & 6.81 & WLAN, Wi-Fi \\
\hline Tighezza et al. [16] & Polyethylene terephthalate & $60 \times 75$ & 6.0 & 5 & $5 \mathrm{G}$ \\
\hline Simorangkir et al. [20] & Polydi methylsiloxane & $80 \times 67$ & 6.0 & 4.53 & UWB \\
\hline Proposed Antenna & Nickel aluminate & $25 \times 27$ & 2.35 & 4.75 & C-Band \\
\hline
\end{tabular}

\section{Conclusions}

The flexible antenna has been analyzed, designed and developed on prepared flexible nickel aluminate $\left(\mathrm{NiAl}_{2} \mathrm{O}_{4}\right)$ material. The developed flexible nickel aluminate $\left(\mathrm{NiAl}_{2} \mathrm{O}_{4}\right)$ material has dielectric permittivity of 4.97 as well as loss tangent of 0.007 at $42 \%$ concentration of nickel. The developed antenna shows that simulated resonance bandwidth is from 7.05 to $8.72 \mathrm{GHz}$ (bandwidth of $1.67 \mathrm{GHz}$ ), whereas the measured resonance bandwidth is from 6.5 to $8.85 \mathrm{GHz}$ (bandwidth of $2.35 \mathrm{GHz}$ ). As a result, the fabricated flexible antenna is applicable for $\mathrm{C}$-band applications with the maximum measured gain of $4.75 \mathrm{dBi}$. The optimal performances of the compact flexible antenna validate has potential as a suitable candidate for microwave frequency region applications in the near future.

Author Contributions: M.A.R. and M.R.I.F. made substantial contributions to conception, materials preparation, design, characterization and analysis. E.A. participated in the analysis and critical revision of the article for important intellectual content. M.T.I. and M.S. provided necessary instructions for experimental purposes.

Funding: This work was supported by the Fundamental Research Grant, Ministry of Education, Code: FRGS/1/2018/TK04/UKM/02/13.

Conflicts of Interest: The authors declare no conflict of interest.

\section{References}

1. AbuTarboush, H.F.; Shamim, A. Paper-Based Inkjet-Printed Tri-Band U-Slot Monopole Antenna for Wireless Applications. IEEE Antennas Wirel. Propag. Lett. 2012, 11, 1234-1237. [CrossRef]

2. Faraj, M.G.; Ibrahim, K.; Ali, M.K.M. PET as a plastic substrate for the flexible optoelectronic applications. Optoelectronics and Advanced Materials. Rapid Commun. 2011, 5, 879-882.

3. Khaleel, H.R.; Al-Rizzo, H.M.; Rucker, D.G. Compact Polyimide-Based Antennas for Flexible Displays. J. Disp. Technol. 2012, 8, 91-97. [CrossRef]

4. Jiang, Z.H.; Brocker, D.E.; Sieber, P.E.; Werner, D.H. A Compact, Low-Profile Metasurface-Enabled Antenna for Wearable Medical Body-Area Network Devices. IEEE Trans. Antennas Propag. 2014, 62, 4021-4030. [CrossRef]

5. Ramli, M.N.; Soh, P.J.; Jamlos, M.F.; Lago, H.; Aziz, N.M.; Al-Hadi, A.A. Dual-band wearable fluidic antenna with metasurface embedded in a PDMS substrate. Appl. Phys. A 2017, 123, 149. [CrossRef]

6. Sun, Y.; Yuk, T.I.; Cheung, S.W. Design of a textile ultra-wideband antenna with stable performance for body-centric wireless communications. IET Microwaves Antennas Propag. 2014, 8, 1363-1375. [CrossRef]

7. Bengio, E.A.; Senic, D.; Taylor, L.W.; Tsentalovich, D.E.; Chen, P.; Holloway, C.L.; Babakhani, A.; Long, C.J.; Novotny, D.R.; Booth, J.C.; et al. High efficiency carbon nanotube thread antennas. Appl. Phys. Lett. 2017, 111, 163109. [CrossRef]

8. Ahamed, E.; Hasan, M.M.; Faruque, M.R.I.; Bin Mansor, M.F.; Abdullah, S.; Islam, M.T. Left-handed metamaterial inspired by joint T-D geometry on flexible $\mathrm{NiAl}_{2} \mathrm{O}_{4}$ substrate. PLOS ONE 2018, 13, e0199150. [CrossRef] [PubMed]

9. Hasan, M.M.; Faruque, M.R.I.; Islam, M.T. Dual Band Metamaterial Antenna For LTE/Bluetooth/WiMAX System. Sci. Rep. 2018, 8, 1240. [CrossRef] [PubMed]

10. Anagnostou, D.E.; Gheethan, A.A.; Amert, A.K.; Whites, K.W. A Direct-Write Printed Antenna on Paper-Based Organic Substrate for Flexible Displays and WLAN Applications. J. Disp. Technol. 2010, 6, 558-564. [CrossRef] 
11. Choi, S.W.; Lee, H.J.; Lee, J.Y.; Lee, K.B. CPW-fed compact flexible antenna based on a zeroth-order resonator. In Proceedings of the 2011 IEEE International Symposium on Antennas and Propagation (APSURSI), Spokane, WA, USA, 3-8 July 2011.

12. Jalil, M.E.; Rahim, M.K.A.; Abdullah, M.A.; Ayop, O. Compact CPW-fed Ultra-wideband (UWB) antenna using denim textile material. In International Symposium on Antennas and Propagation. In Proceedings of the 2012 International Symposium on Antennas and Propagation (ISAP), Nagoys, Japan, 29 October-2 November 2012.

13. Mesquita, J.M.; Pires, N.; Moreira, A.A. Influence of deformations on the matching of a flexible dual-band antenna. In Proceedings of the 2013 7th European Conference on Antennas and Propagation (EuCAP), Gothenburg, Sweden, 8-12 April 2013.

14. Porter, E.; Walls, G.; Zhou, Y.; Popovic, M.; Schwartz, J.D. A Flexible Broadband Antenna And Transmission Line Network for a Wearable Microwave Breast Cancer Detection System. Prog. Electromagn. Res. Lett. 2014, 49, 111-118. [CrossRef]

15. Jung, Y.H.; Qiu, Y.; Lee, S.; Shih, T.Y.; Xu, Y.; Xu, R.; Lee, J.; Schendel, A.A.; Lin, W.; Williams, J.C.; et al. A compact parylene coated WLAN flexible antenna for implantable electronics. IEEE Antenn. Wirel. Propag. Lett. 2015, 15, 1382-1385. [CrossRef]

16. Tighezza, M.; Rahim, S.K.A.; Islam, M.T. Flexible wideband antenna for 5G applications. Microw. Opt. Technol. Lett. 2017, 60, 38-44. [CrossRef]

17. Anguera, J.; Daniel, J.P.; Borja, C.; Mumbrú, J.; Puente, C.; Leduc, T.; Sayegrih, K.; Roy, P.V. Metallized Foams for Antenna Design: Application to Fractal-Shaped Sierpinski-Carpet Monopole. Prog. Electromagn. Res. 2010, 104, 239-251. [CrossRef]

18. Rahman, M.A.; Ahamed, E.; Faruque, M.R.I.; Islam, M.T. Preparation of $\mathrm{NiAl}_{2} \mathrm{O}_{4}$-Based Flexible Substrates for Metamaterials with Negative Dielectric Properties. Sci. Rep. 2018, 8, 14948. [CrossRef] [PubMed]

19. Kaur, A.; Aastha; Kalra, P.; Sidhu, E. Flexible novel trident shaped microstrip patch antennas design employing Teflon substrate. In Proceedings of the Flexible novel trident shaped microstrip patch antennas design employing Teflon substrate, Allahbad, India, 21-22 October 2016.

20. Simorangkir, R.B.V.B.; Kiourti, A.; Esselle, K.P. UWB Wearable Antenna With a Full Ground Plane Based on PDMS-Embedded Conductive Fabric. IEEE Antennas Wirel. Propag. Lett. 2018, 17, 493-496. [CrossRef] 